\title{
DESIGN FOR SUSTAINABILITY AND INNOVATION: A KANSEI ENGINEERING EVALUATION OF THE ADAPTIVE REUSE OF OLD BUILDINGS
}

\author{
Shao, Dan (1); Nagai, Yukari (2); Sosa, Ricardo (3) \\ 1: Japan Advanced Institute of Science and Technology, Japan, Dalian Polytechnic University, China; \\ 2: Japan Advanced Institute of Science and Technology, Japan; 3: Auckland University of Technology, \\ New Zealand
}

\begin{abstract}
The aim of our study was to use Kansei Engineering Evaluation to examine the renewal of old buildings with sustainability and innovation by comparing to new buildings. First, we conducted a questionnaire survey, with 84 participants, on 18 buildings from Asian and European countries; the survey used 16 adjectives. Second, we studied the characteristics of new and renewed old buildings in terms of the elements crucial to sustainable and innovative design. The results suggest that the adaptive reuse of old buildings in more sustainable than constructing new buildings. Further, the adjectives preferred by the survey show that the adaptive reuse of old buildings has higher influence with character of "creative" from the innovation viewpoint. This paper presents a project to address sustainability and innovation of adaptive reused of old building at a later stage. This study contributes to the renewal of existing infrastructure to improve its longevity and chance of future reuse, and to ensure environmental sustainability for future society.
\end{abstract}

Keywords: Adaptive Reuse Old Buildings, Sustainability, Creativity, Evaluation, New buildings

Contact:

Shao, Dan

Japan Advanced Institute of Science and Technology, Japan; Dalian Polytechnic University, China Advanced Science and Technology; School of Art and Design

Japan

sd17@163.com

Cite this article: Shao, D., Nagai, Y., Sosa, R. (2019) 'Design for Sustainability and Innovation: A Kansei Engineering Evaluation of the Adaptive Reuse of Old Buildings', in Proceedings of the 22nd International Conference on Engineering Design (ICED19), Delft, The Netherlands, 5-8 August 2019. DOI:10.1017/dsi.2019.329 


\section{INTRODUCTION AND LITERATURE REVIEW}

Design for sustainability invites designers to re-examine the relationship between human development and environmental issues, constantly seeking change in practice (Vezzoli \& Manzini, 2008). Sustainable design is of increasing relevance not only for the design of new buildings, but also for the renewal of old buildings (Sayigh, 2013). Upgrading old buildings presents clear advantages over new buildings (TEC, 2008). Adaptive reuse of old buildings is a process that transforms an obsolete or ineffective project into a new one, by renovating and reusing existing structures for new uses (Reuse, 2004). The adaptive reuse of old buildings could extend a building's lifecycle, reducing the influence on the environment. The trend towards increasing sustainability by finding new functional aims for old buildings, rather than demolishing them and constructing a new one, has shed light on the importance of the concept of future building (Conejos et al., 2014).

Meanwhile, much of the contemporary architecture looks the same in New York, Paris, New Delhi, and Tokyo, and such international architecture is equally inappropriate wherever it is built, as it is not sustainable for local climates (Lechner, 2014). Against a backdrop of globalization, strengthening the regional and cultural characteristics and enhancing the heterogeneous structure of buildings through innovative design is one of our considerations. Design innovations are those that make a significant difference in the market through the creation of new meanings (Verganti \& Dell'Era, 2009). Opportunities for design innovation are also present in the adaptive reuse of old designs (Henderson \& Clark, 1990).

The main research questions that guide this work include: How may the adaptive reuse of old buildings lead to innovative and sustainable designs? How may sustainability and innovation be integrated in a better environmental design for our future society? What specific characteristics should such buildings have? This research seeks to understand the combination of sustainability and innovation in the adaptive reuse of old buildings across geographic contexts.

\section{RESEARCH AIM AND MOTIVATION}

The current research on the adaptive reuse of old buildings mostly focuses on advantages from the perspective of sustainable design. Many abandoned old buildings hold great potential for adaptive reuse (Stas, 2007). Studies tend to focus on the analysis of individual cases and there is an emphasis on radical innovation driven by technology. A wide range of examples analyze the merits of individual cases (Bloszies, 2013). Only a few studies combine the two aspects of sustainability and innovation into one category.

Designers can translate users' preferences into their redesigns of old buildings by including characteristics that people identify and value (Govers et al., 2003). Users' emotional needs should be considered as a design criterion (Luo \& Hong, 2015). Therefore, we developed a questionnaire for designers to analyze two types of buildings using adjectives to describe the characteristics of buildings with the Kansei Engineering method. A powerful consumer oriented technology for design development, Kansei engineering translates participant's feelings (Nagamachi, 2010).This paper aims to:

1. Determine if the adaptive reuse of old buildings is superior to the perceived value of sustainability of new buildings.

2. Identify adjectives that can highlight sustainability and innovation in renewal of old buildings, in order to assist designers to integrate the emotional information into their designs.

3. Illustrate a specific case study of an adaptive reuse of an old building that combines sustainability and innovation.

\subsection{Hypotheses}

This study is informed by the 5R's (Revalue, Renew, Reuse, Reduce, and Recycle) of Sustainability (Zhou, 2011) and the two elements (practicality and originality) of innovative design (Finke et al., 1992). In order to study the perception of 84 participants using pictures of new buildings and adaptive reuse of old buildings, this paper uses the Kansei Engineering method to evaluate the two types of buildings, in examining the following hypotheses. 


\subsubsection{Hypothesis 1 (H1)}

By comparing the respondents' evaluation of the cases selected, we look for differences in perception between the old and new buildings, in trying to assess whether the adaptive reuse of old buildings for sustainability is preferable to constructing new buildings.

\subsubsection{Hypothesis $2(\mathrm{H} 2)$}

What kind of adjectives may accurately highlight sustainability and innovation? The suitable adjectives that express the perception of innovation of the adaptive reuse of old buildings is expected to be derived from the questionnaire.

\section{METHODOLOGY}

\subsection{Data collection}

\subsubsection{Collect picture samples}

Through the investigation of adaptive reuse of old buildings in books and networks, 50 prominent cases were used to collect samples from two Asian countries (Japan and China) and developed European countries (including France, Italy, Swiss, and UK etc.). Irrespective of their location, we found that the old buildings in the living space are demolished and replaced by new buildings, even if the original function was a living space, which was more generally transformed into public spaces such as hotels and offices. Hence, we chose the type of buildings characterizing the public space.

After group discussion and multi-scale analysis, 4 cases were found in each type of architectural sample: Chinese, Japanese, and European countries including a total of 12 cases of adaptive reuse of old buildings; in order to explain the problem more favorably, we used the same method to find each type of architectural sample with 2 cases in China, Japan, and European, resulting in a total of 6 cases of new buildings. In addition, we selected the picture with the highest number and clearest features from each case. The 18 samples are shown in Figure 1.

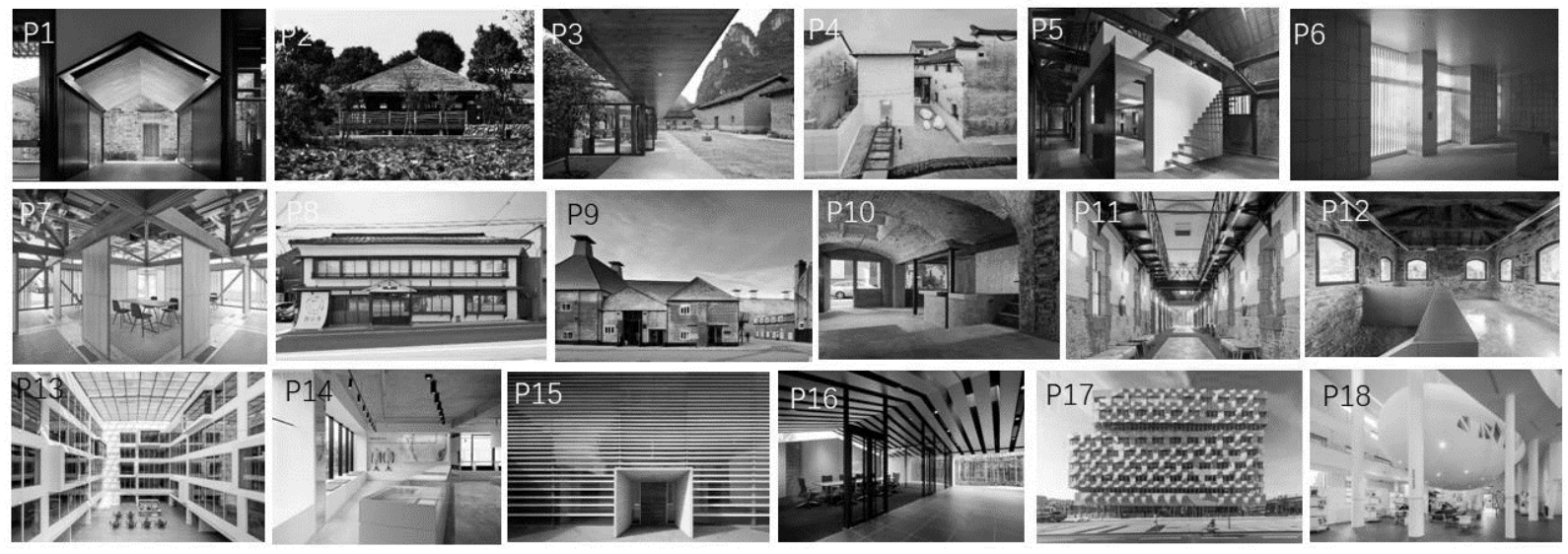

Figure 1. Selected representative samples

\subsubsection{Screen representative vocabularies}

The researchers developed a semantic differential vocabulary for evaluation through brainstorming, Internet, and suggestions of experts (comprising professional teachers and senior designers). Through initial screening, modifying, and classifying, 16 pairs of adjectives conveying a clear intention were chosen as shown in Table 1. 
Table 1. Sixteen selected pairs of adjectives used to assess the buildings

\begin{tabular}{|l|c|c|r|}
\hline Bad - Good & Ugly - Beautiful & Dissonant - Harmonious & Constrained -Free \\
\hline Dull-Brilliant & Boring-Interesting & Disorderly-Orderly & Dirty - Clean \\
\hline $\begin{array}{l}\text { Uncomfortable - } \\
\text { Pleasant }\end{array}$ & Disturbed -Settled & Inorganic-Organic & $\begin{array}{r}\text { Impoverished- } \\
\text { Luxurious }\end{array}$ \\
\hline Unsafe-Safe & Calm- Excitable & Conservative-Creative & Unfamiliar-Familiar \\
\hline
\end{tabular}

\subsubsection{Design questionnaire}

The questionnaire included interior and exterior pictures in old buildings and new buildings. The semantic differential (SD) method was used to evaluate the selected 18 samples. The SD method (Osgood et al. 1957) had a seven-point scale (1: low and 7: high) and was used with 16 pairs of adjectives to form a survey (see examples in table 2). Each adjective pair took 2-3 seconds and each case took 48 seconds to complete, and the overall time for each participant was about 20minutes.

Table 2. Example of SD method on a seven-point scale for adjective pairs of ugly-beautiful

\begin{tabular}{|l|l|l|l|r|r|r|}
\hline $\begin{array}{l}\text { Very } \\
\text { ugly }\end{array}$ & Quite ugly & Slightly ugly & Neutral & Slightly beautiful & Quite beautiful & Very beautiful \\
\hline 1 & 2 & 3 & 4 & 5 & 6 & 7 \\
\hline
\end{tabular}

\subsubsection{Evaluate semantically differential words}

This study used a network evaluation method through the "questionnaire star" software by selecting 84 participants of undergraduates in grade four in China, with males were 31, females were 53, who had a professional background in environmental design and will be designers in the future. Questionnaires were distributed and semi-structured interviews were conducted.

\subsection{Data analysis}

There were 18 pictures of two types of buildings. The adaptive reuse of old buildings was divided for three groups: China, represented by P1, P2, P3, and P4; Japan, represented by P5, P6, P7, and P8; European countries, represented by P9, P10, P11, and P12. New buildings included P13 and P14 in China, P15 and P16 in Japan, and P17and P18 in European countries. We used an abbreviation A to express adjective pairs (A1: Bad - Good; A2: Ugly - Beautiful; A3: Dissonant - Harmonious; A4: Constrained - Free; A5: Dull - Brilliant; A6: Boring - Interesting; A7: Disorderly - Orderly; A8: Dirty - Clean; A9: Uncomfortable - Pleasant; A10: Disturbed - Settled; A11: Inorganic-Organic; A12: Impoverished-Luxurious; A13: Unsafe - Safe; A14: Calm - Excitable; A15: Conservative Creative; and A16: Unfamiliar - Familiar). For this stage, we got the mean scores on each pair of adjectives for the 18 pictures, as demonstrated below in Table 3.

Table 3. Average of semantic differential evaluation

\begin{tabular}{|l|l|l|l|l|l|l|l|l|l|l|l|l|l|l|l|r|r|}
\hline Pic. & A1 & A2 & A3 & A4 & A5 & A6 & A7 & A8 & A9 & A10 & A11 & A12 & A13 & A14 & A15 & A16 & Mean \\
\hline P1 & 5.18 & 5.04 & 5.28 & 4.54 & 4.52 & 4.23 & 5.52 & 5.74 & 4.69 & 5.52 & 4.62 & 5.31 & 4.84 & 5.86 & 4.24 & 4.17 & 4.96 \\
\hline P2 & 5.02 & 5.02 & 5.21 & 5.05 & 4.95 & 4.76 & 4.7 & 4.67 & 5.08 & 4.69 & 5.85 & 4.43 & 4.6 & 5.52 & 3.74 & 4.9 & 4.89 \\
\hline P3 & 6.12 & 5.99 & 5.75 & 5.74 & 6.02 & 5.82 & 5.86 & 5.88 & 6.00 & 5.65 & 6.05 & 5.67 & 5.7 & 5.93 & 5.52 & 5.77 & 5.84 \\
\hline P4 & 6.02 & 6.1 & 5.9 & 5.64 & 5.83 & 5.62 & 5.58 & 5.8 & 5.88 & 5.69 & 5.6 & 5.62 & 5.66 & 6.00 & 5.01 & 5.76 & 5.73 \\
\hline P5 & 5.49 & 5.25 & 5.35 & 4.94 & 4.45 & 5.08 & 5.18 & 5.63 & 4.83 & 5.19 & 4.68 & 5.3 & 4.39 & 4.93 & 5.27 & 4.68 & 5.04 \\
\hline P6 & 5.30 & 5.21 & 5.43 & 4.67 & 5.07 & 4.55 & 5.45 & 5.73 & 5.1 & 5.49 & 4.8 & 5.12 & 5.27 & 5.55 & 4.5 & 5.12 & 5.15 \\
\hline P7 & 5.63 & 5.49 & 5.58 & 5.17 & 5.92 & 5.37 & 5.51 & 5.73 & 5.13 & 5.17 & 4.85 & 5.19 & 4.88 & 5.21 & 5.21 & 4.82 & 5.3 \\
\hline P8 & 5.58 & 5.38 & 5.64 & 4.83 & 5.32 & 4.83 & 5.58 & 5.64 & 5.23 & 5.44 & 4.81 & 4.94 & 5.5 & 5.64 & 4.57 & 5.23 & 5.26 \\
\hline P9 & 5.09 & 5.46 & 5.13 & 5.7 & 5.9 & 5.54 & 5.7 & 5.42 & 5.56 & 5.72 & 5.92 & 4.8 & 5.42 & 4.96 & 3.75 & 4.35 & 5.49 \\
\hline P10 & 4.89 & 4.51 & 4.76 & 4.45 & 4.21 & 4.5 & 4.68 & 4.73 & 4.35 & 4.94 & 4.18 & 4.44 & 4.64 & 4.94 & 4.13 & 4.24 & 4.54 \\
\hline P11 & 5.43 & 5.27 & 5.01 & 4.9 & 5.24 & 5.01 & 5.35 & 5.21 & 4.89 & 4.99 & 4.58 & 5.02 & 4.84 & 4.77 & 4.57 & 4.68 & 4.99 \\
\hline
\end{tabular}




\begin{tabular}{|l|c|c|c|c|c|c|c|c|c|c|l|l|l|l|l|l|r|}
\hline P12 & 5.01 & 4.8 & 4.6 & 4.56 & 4.85 & 4.43 & 4.65 & 5.06 & 4.36 & 4.96 & 4.58 & 4.65 & 4.42 & 4.87 & 4.85 & 4.4 & 4.69 \\
\hline P13 & 5.35 & 5.05 & 5.18 & 4.46 & 6.1 & 4.39 & 5.92 & 5.98 & 4.71 & 5.81 & 4.00 & 5.02 & 4.84 & 5.38 & 4.76 & 4.31 & 5.08 \\
\hline P14 & 5.48 & 5.42 & 5.52 & 5.24 & 5.77 & 5.19 & 5.37 & 5.85 & 5.05 & 5.45 & 4.36 & 5.46 & 5.08 & 5.48 & 5.35 & 4.79 & 5.3 \\
\hline P15 & 5.19 & 5.06 & 5.05 & 4.31 & 4.92 & 4.81 & 5.6 & 5.52 & 4.53 & 5.3 & 4.05 & 5.14 & 4.64 & 4.87 & 5.25 & 4.37 & 4.91 \\
\hline P16 & 5.25 & 5.17 & 4.93 & 4.71 & 4.51 & 4.69 & 4.79 & 4.99 & 4.65 & 4.92 & 4.2 & 4.51 & 4.79 & 4.92 & 5.07 & 4.39 & 4.82 \\
\hline P17 & 5.4 & 4.94 & 4.96 & 4.95 & 5.25 & 5.26 & 5.01 & 5.44 & 4.85 & 4.92 & 4.29 & 5.27 & 4.61 & 4.23 & 5.65 & 4.46 & 4.97 \\
\hline P18 & 5.7 & 5.6 & 5.27 & 5.33 & 5.83 & 5.36 & 5.23 & 5.64 & 5.36 & 5.15 & 4.82 & 5.36 & 4.94 & 4.95 & 5.6 & 4.81 & 5.31 \\
\hline
\end{tabular}

\section{RESULTS}

\subsection{Relationship between adaptive reuse of old buildings and new buildings ( $\mathrm{H} 1)$}

According to the "mean" of each picture, "mean" was the average of each score which represent the preferences of participants, the left adjectives represent the lowest score, the right ones are the high score. we collected the pictures in one group of old buildings renewal which were P1 (4.96), P2 (4.89), P3 (5.84), P4 (5.73), P5 (5.04), P6 (5.15), P7 (5.3), P8 (5.26), P9 (5.49), P10 (4.54), P11 (4.99) \& P12 (4.69) respectively, the average of old building renewal was 5.16; while in the other groups of new buildings which were P13 (5.08), P14 (5.3), P15 (4.91), P16 (4.82), P17 (4.97) \& P18 (5.31) respectively; the average of new buildings was 5.06. Therefore, 5.16 of old buildings renewal is overweight the 5.06 of new buildings. Meanwhile, Georgiev et al. (2012) state that "comfort" which is a pleasurable feeling of ease and well-being experienced, in other words, "uncomfortable - pleasant" this adjectives pair of A9 extremely express the level of preference. From the result P1(4.69) to P12 (4.36) in old buildings renewal in this pair, the average is 5.19; from P13(4.71) to P17(5.36) in new buildings, the average is 4.86 . Hence, 5.19 higher than 4.86 , from the viewpoint of this adjective pair, old buildings renewal also exceed to new one.

Whilst the difference is marginal between these groups, the results suggest that the adaptive reuse of the old buildings is superior to the new buildings, which confirms the relevance and value of sustainable design. Just like Bergman (2012) stated, adaptive reuse of old buildings can produce higher levels of sustainable design.

\subsection{Preferred adjectives words of two kinds of architecture (H2)}

Principal component analysis (PCA) was carried out to identify the perceptions that were related or similar. PCA was applied to investigate relationships between adjectives in both types of buildings (Hypothesis 2). The purpose of the PCA is to reduce dimensionality in datasets where there are several interrelated variables, and preserve the variation in the dataset as much as possible (Jolliffe, 2002).

We input the data into SPSS to analyze the factors according to the Kaiser-Meyer-Olkin (KMO) and Batlett Test measure of sampling adequacy. The main role of the KMO statistic is to detect the adequacy of the collected samples and to test the degree of partial correlation between the variables. That is, whether is to perform factor analysis. According to Kaiser (1974), the KMO value should be between 0 and 1 . The more closer to 1 , the more suitable for factor analysis. If the score was over 0.7 , the result is more credible. It was 0.957 for renewal of old buildings and 0.929 for new buildings; Table 4 shows the KMO scores for the two types of buildings, so we regarded the mean of result on table 3 as believable.

The Bartlett sphere test is a test of whether variables are independent of one another. However, when the $\mathrm{p}$ value reached a significant level ( $\mathrm{p}<0.05)$, it was suitable for factor analysis $(\mathrm{Wu}, 2010)$. It was found from the table that Barlett's ball value was 0.000 , reaching a significant level of 0.05 , indicating that the scale is suitable for factor analysis. Therefore, two types of buildings of factor analysis can be used to test the validity of the scale through KMO and Bartlett's Test. 
Table 4. KMO and Bartlett's Test scores in the two types of buildings

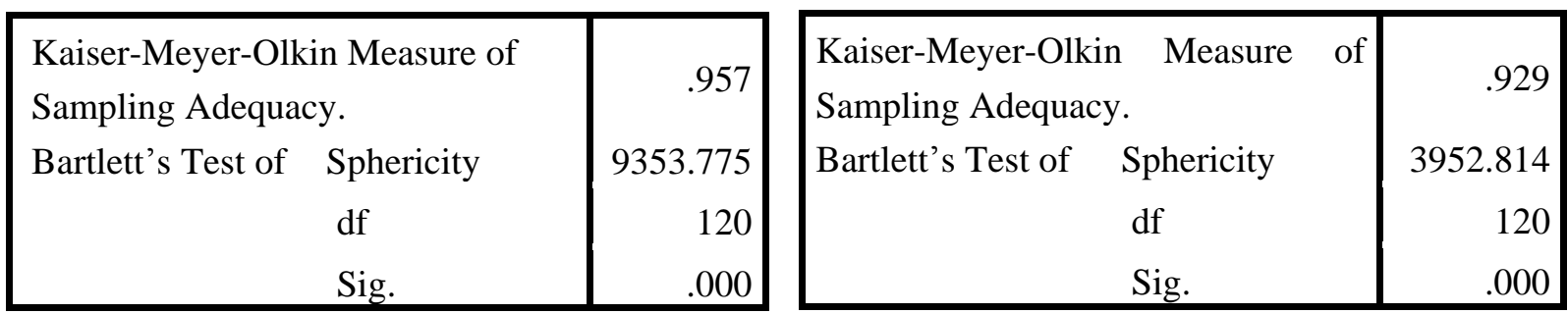

\subsubsection{Adjectives in adaptive reuse of old buildings}

The left part of Table 5 shows the comparison of the principal components' factor loadings in renewal of old buildings for the two clusters. The top five factors in component 1 denoting Creative scoring .782, Interesting scoring .769, Free scoring .690, Alive scoring .668, and Pleasant scoring .644; and component 2 with the top five factors being Settled scoring .769; Calm scoring .769; Orderly scoring.719; Clean scoring .671, and Harmonious scoring .643. The left adjectives with the lower scores, we ignore them. Table 5 is shown below.

Table 5. Rotated Component Matrix ${ }^{\mathrm{a}}$ in renewal of old buildings and new buildings

\begin{tabular}{|l|c|c|}
\hline \multirow{2}{*}{} & \multicolumn{2}{|c|}{ Component } \\
\cline { 2 - 3 } & 1 & 2 \\
\hline Conservative - Creative & .782 & \\
Boring-Interesting & .769 & \\
Constrained -Free & .690 & \\
Inorganic - Organic & .668 & \\
Uncomfortable - Pleasant & .644 & \\
Impoverished - Luxurious & .608 & \\
Unfamiliar - Familiar & .583 & \\
Dull - Brilliant & .576 & \\
Ugly-Beautiful & .574 & .524 \\
Disturbed - Settled & & .769 \\
Excitable - Calm & & .769 \\
Disorderly- Orderly & & .719 \\
Dirty - Clean & & .671 \\
Dissonant-Harmonious & & .643 \\
Unsafe - Safe & & .579 \\
Bad - Good & .562 & .578 \\
\hline
\end{tabular}

\begin{tabular}{|l|c|c|c|}
\hline \multirow{2}{*}{} & \multicolumn{3}{|c|}{ Component } \\
\cline { 2 - 4 } & 1 & 2 & 3 \\
\hline Conservative - Creative & .756 & & \\
Constrained -Free & .754 & & \\
Boring-Interesting & .752 & & \\
Uncomfortable - Pleasant & .605 & & \\
Bad - Good & .599 & & \\
Ugly-Beautiful & .590 & .505 & \\
Impoverished - Luxurious & .580 & & \\
Dirty - Clean & & .773 & \\
Disorderly- Orderly & & .699 & \\
Disturbed - Settled & & .699 & \\
Dull - Brilliant & & .661 & \\
Dissonant-Harmonious & & .562 & \\
Excitable - Calm & & & .691 \\
Unsafe - Safe & & & .682 \\
Unfamiliar - Familiar & & & .676 \\
Inorganic - Organic & .542 & & .586 \\
\hline
\end{tabular}

a. Rotation converged in 3 iterations

\subsubsection{Adjectives in new buildings}

The right part of Table 5 shows the comparison of the principal components' factor loadings in new buildings for the three clusters. The higher score meant a similar relationship with the new buildings. Component 1 with the top five factors being Creative scoring .756, Free scoring .754, Interesting scoring .752, Pleasant scoring .605, and Good scoring .599; component 2 with the top four factors being Clean scoring .773, Settled scoring .699, Orderly scoring .699; Brilliant scoring .661, and Harmonious scoring .562; and component 3 with the top three factors being calm scoring.691, Safe scoring .682, and Familiarscoring.676.

\subsubsection{Summarizing the semantically differential words}

Through PCA and Rotation Sums of Squared Loadings, we got the results. The percentage of variance in renewal of old buildings was $31.031 \%$ in component 1 and $29.149 \%$ in component 2 . The 
cumulative variance contribution rate was $60.18 \%$, which meant that the two factors explain the information 60.18 percentage, reaching the $60 \%$ minimum standard, and the factor load of each item in the grid dimension was greater than 0.5, indicating that the extracted factor could be accepted. Through the above analysis, the scale of this study had good construct validity. The respective higher scoring words were Creative.782 and Interesting .769 in component 1 and Settled .769 in component 2 ; hence, the adjectives to highlight the adaptive reuse of old buildings were creative, interesting, and settled.

The percentage of variance in new buildings was $24.818 \%$ in component 1 with Creative.756, Free .754 , and Interesting .752; $21.976 \%$ in component 2 with Clean .773; and $14.928 \%$ in component 3 , in which the others with lower influence was discarded. The cumulative variance contribution rate was $61.722 \%$, and the factor load of each item in the grid dimension was greater than 0.5 , the same as previous analysis, the scale of this study also had a good construction validity. Therefore, we used the adjectives creative, free, and interesting to describe the new buildings. To see them clearly, we chose the right polar adjectives to express in two types of buildings (Figure 2-3).

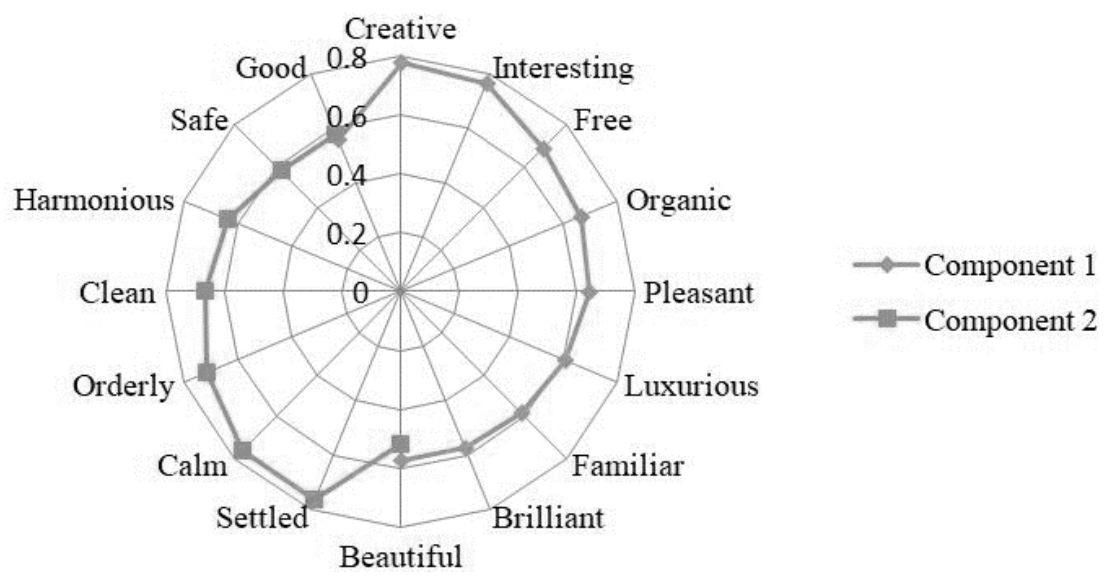

Figure 2. Radar plot of adjective words in renewal of old buildings

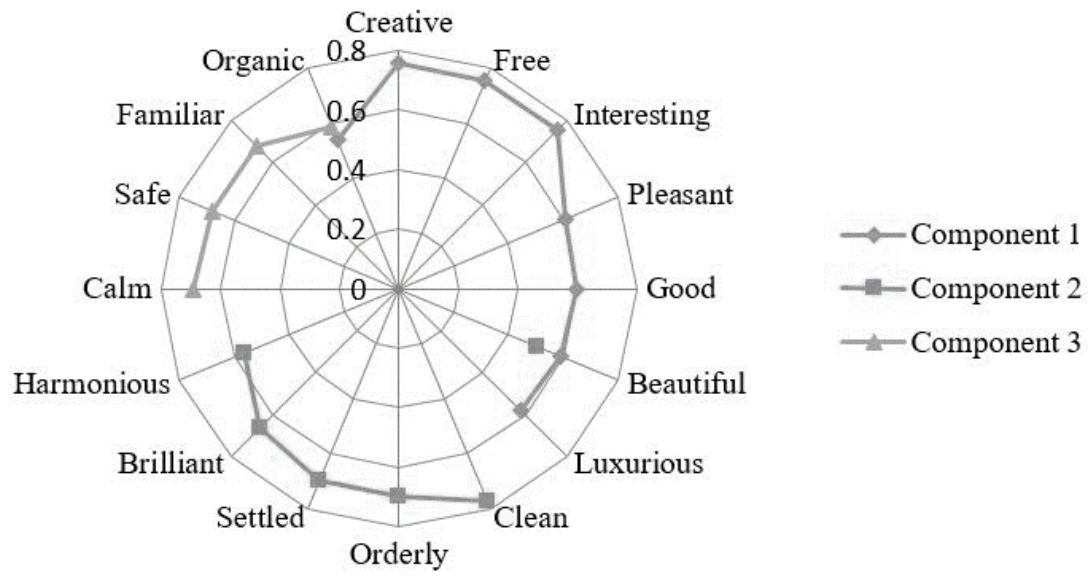

Figure 3. Radar plot of adjective words in new buildings

\section{DIscussion}

\subsection{Adaptive reuse of old buildings was superior to construction of new buildings}

From the results of Hypothesis 1, it can be concluded that adaptive reuse of old buildings was superior to construction of new buildings due to the followings reasons.

Firstly, there are clear environmental sustainability benefits that can make this option better than constructing new buildings. From the feedback of semi-structured interviews, most of them agree that, new buildings increase the new environmental burden in the construction process. For instance, they generate new resources and energy consumption, produce new waste, and occupy more land. Such as the total cost is $10 \mathrm{M} €$ excluding VAT in P18. However, for the adaptive reuse of old buildings, the 
potential of the buildings will be maximized if they are reused before they are completely useless, take P9 for example, recycling materials with agricultural roofing sheet and manmade slates are used for economy but also to maintain a simple, unadorned aesthetic. It could therefore be reasonably argued that adaptive reuse is a method of extending the useful life of buildings and hence their sustainability through a combination of improvement and conversion (Bullen, 2007).

Secondly, there are some social sustainability benefits. Renewal of old buildings may have a characteristic that significantly contributes to the culture of the society. Such as P10, the project is a contextual dialogue with history, all the elements were put into the raw original state or it was rebuilt raw - a tribute to the material. The architectonic-social aspect is playing a minor part but it is still the same house from the outside. The reuse of these old buildings is important and maintains their intrinsic cultural values, while new buildings do not have such features. Therefore, from a social sustainability perspective, it is preferable to perform adaptive reuse of old buildings.

\subsection{The reason for preferred adjective words}

Results showed the preferred adjectives in old buildings renewal were: creative, interesting, and settled, which response to $\mathrm{H} 2$. It means settled and creative would positively correlate with the sustainability and innovation. The reasons why these words were preferred by participants are as following.

On the one hand, the mean of "settled" in the old buildings renewal is 5.25, and same as the new buildings. From the feedback of participants in semi-structured interviews, they are convinced that architecture is formed by an interface of enclosed space, and its spatial extension and shape are also determined. Just like Zhou (2011) argue that the ecosystem itself has ecological balance ability and strong closure, that is, the ability to regulate and restore its own stable state or reach equilibrium. Therefore, the building is an ecological subsystem with a relatively stable operation mode at a microscopic level. The old building is no exception. It is a link and stage of continuous energy and material flow in the ecosystem. From this point of view, it is stable. "Settled" adjective might play a positive role in sustainable environmental design.

On the other hand, as we mentioned before, originality is the most important element in innovation design. The corresponding adjective is "creative." In component 1 in two types of buildings, "creative" denoted scoring is.782 and .756, which got the highest scores than other words. In the old buildings' renewal, these old and weather-resistant old buildings retain their most essential things when they meet with the new materials and new technology in modern architectural vocabulary. It is easier for designers to develop creative spatial effects after balance the old structure and new material. This approach can inject fresh blood into the old buildings, so that the participants can feel the creative effects in the old buildings' renewal. As creative and settled were used to describe them, we infer that these adjectives are the preferred ones for describing the reuse of old buildings.

\section{A PROJECT ILLUSTRATION}

Here, we describe a project for the adaptive reuse of an old building, called the Harvard House Zero Laboratory (Snøhetta, 2018), see Figure 4-5. The project considered the adaptive reuse of the pre1940s building in Cambridge that housed this laboratory's headquarters. The aim was to help us understand the renewal of old buildings in new ways. The building represents an exemplary case of sustainability and innovation. Its design was driven by ambitious performance targets from the outset, including the implementation of near zero energy heating and cooling, zero electric lighting during the day, $100 \%$ natural ventilation, and zero carbon emissions. The intention for all this is for the building to produce more energy over its lifetime than was used in its renovation and subsequent operation. House Zero Laboratory challenged us to rethink the routine of building design and make a stable operation mode at a sustainable level to express the adjective "settled".

The laboratory provides users with creative technological skill for research and exploration. The building's architecture also comprises cutting-edge technology and applications of established, lowtech architectural design solutions. Take the natural ventilation as an example: the ventilation is controlled by a window actuation system that employs sophisticated software and sensor arrays to automatically open and close windows as required maintaining a quality internal environment throughout the year. This way above mentioned to express "creative". 
This laboratory can function as a new model of sustainability and innovation in old buildings renewed for future society.
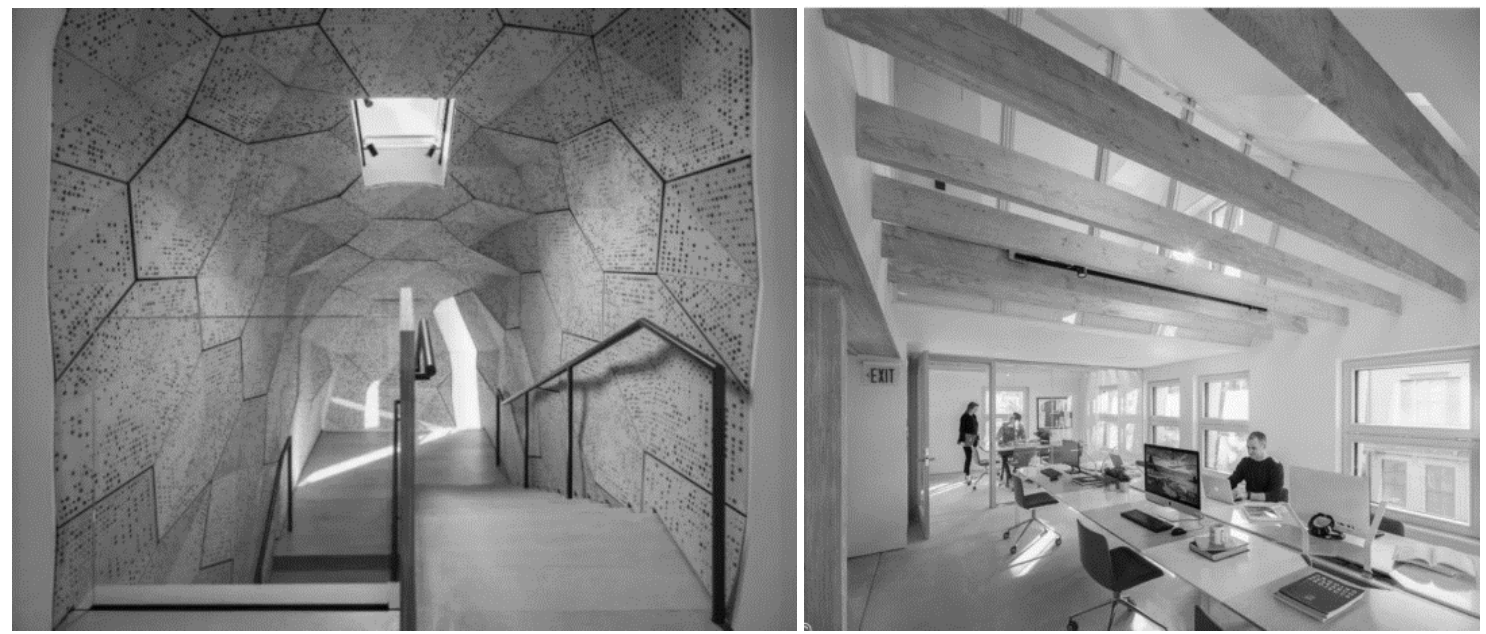

Figure 4-5. Harvard House Zero Laboratory

\section{CONCLUSIONS}

The research presented in this paper shows two results in relation to sustainability and innovation of adaptive design. One is that adaptive reuse of old buildings can be superior to constructing new buildings, and the other is that "creative" and "settled" represented by innovation and sustainability are relatively easy to express the adaptive reuse of old buildings.

Since buildings impact the environment significantly, Architects have both the responsibility and the opportunity to lead efforts toward sustainable and creative lifestyles in the future. The adaptive reuse of old buildings is an appropriate way to achieve this goal. Further research will show the typology of the adaptive reuse of old buildings in the public space.

\section{REFERENCES}

Bergman, D. (2013), Sustainable design: A critical guide. Princeton Architectural Press, New York.

Bloszies, C. (2013), Old Buildings New Designs: Architectural Transformations. Princeton Architectural Press, p. 8.

Bullen, P. A. (2007), "Adaptive reuse and sustainability of commercial buildings", Facilities, Vol. 25 No. 1/2, pp. 20-31. https://doi.org/10.1108/02632770710716911

Conejos, S., Langston, C. and Smith, J. (2014), "Designing for better building adaptability: A comparison of adaptSTAR and ARP models", Habitat International, Vol. 41, No. 90, pp. 85-91. http://dx.doi.org/10.1016/j.habitatint.2013.07.002

Finke, R.A., Ward, T.B. and Smith, S.M. (1992), Creative Cognition: Theory, Research, and Applications, The MIT Press, Cambridge, MA.

Georgiev, G. V., Nagai, Y., Taura, T., Noda, S. and Willy, D. (2012), Analysis of User Feelings during Interface Operation: Implictions for Creative Design. In DS 73-2 Proceedings of the 2nd International conference on Design Creativity Volume 2.

Govers, P., Hekkert, P. and Schoormans, J. P. (2003), "Happy, cute and tough: Can designers create a product personality that consumers understand", In Design and emotion, pp. 345-349.

Henderson, R.M. and Clark, K.B. (1990), "Architectural Innovation: The Reconfiguration of Existing Product Technologies and the Failure of Established Firms", Administrative Science Quarterly, Vol. 35, pp. 9-30. http://links.jstor.org/sici?sici=0001-8392\%28199003\%2935\%3A1\%3C9\%3AAITROE\%3E2.0.CO\%3B2-U

Jolliffe, I. T. (2002), "Graphical representation of data using principal components", Principal component analysis. Springer, New York.

Lechner, N. (2014), Heating, cooling, lighting: Sustainable design methods for architects. John Wiley \& Sons, p. 2.

Luo, L.X. and Hong, L. (2015), Kansei Engineering Design, Qsinghua University Press, Beijing, p. 1.

Muratovski, G. (2015), Research for designers: A guide to methods and practice, Sage, preface.

Nagamachi, M. (2010), Kansei Engineering, 2 Volume Set. CRC Press.

Osgood, C. E., Suci, G. J. and Tannenbaum, P. H. (1957), The measurement of meaning, University of Illinois Press, Urbana. 
Reuse, D.A. (2004), "Preserving our Past, Building our Future", Department of environment and heritage. Act: department of environment and heritage, Commonwealth of Australia, Vol. 17, pp. 3-5.

Sayigh, A. (2013), Sustainability, energy and architecture: Case studies in realizing green buildings, Academic Press, p. 7.

Snøhetta. (2018), "Harvard House Zero", http://kuaibao.qq.com/s/20181211B0LBSO00?refer=spider

Stas, N. (2007), "The Economics of Adaptive Reuse of Old Buildings: A Financial Feasibility Study \& Analysis", Master's thesis, University of Waterloo, p. 25.

TEC. (2008), Commercial property and climate change - Exposures and opportunities existing building project. TEC. Verganti, R. and Dell'Era, C. (2009), Design-driven innovation, Boston, MA, p. 2.

Vezzoli, C. and Manzini, E. (2008), Design for environmental sustainability (p. 4), Springer, London, p. 1. Wu, M. (2010), Structural equation modeling: Operation and usage of AMOS [M].

Zhou, H. M. (2011), Sustainable Interior Design Theory, China Construction Pub, Beijing, pp. 25-43. 